\title{
Loss of wavelength selectivity in contour masking and aftereffect following dichoptic adaptation
}

\author{
JACK BROERSE, RAY OVER, and WILLIAM LOVEGROVE
}

\author{
University of Tasmania, Hobart, Australia
}

\begin{abstract}
Two experiments measured the apparent orientation (aftereffect) and the threshold for detection (masking) of a colored grating viewed by one eye after exposure to a colored grating to the same or the opposite eye (monoptic inspection) or after stimulation of one eye by color and the other eye by contours (dichoptic inspection). Under the monoptic condition, the color relationship between the inspection and test stimuli exerted control over the extent of aftereffect and masking when the two stimuli were viewed with the same eye, but not when they were seen with different eyes. Aftereffect and masking were nonselective to wavelength following dichoptic inspection, irrespective of whether the test stimulus was presented to the color-adapted or to the contour-adapted eye. The results support other claims that visual detectors with chromatic and spatial tuning have monocular specificity.
\end{abstract}

There have been many recent demonstrations that adaptation to colored gratings results in color aftereffects that are spatially contingent and in spatial aftereffects that are selective to wavelength (see Sekuler, 1974). Thus a vertical grating shown in white light appears to be a desaturated blue and a horizontal grating has a desaturated orange appearance following a period of exposure to vertical lines in orange light and horizontal lines in blue light (McCollough, 1965). In addition, a vertical grating appears to be tilted clockwise following exposure to counterclockwise tilted lines, and the distortion is greater when the inspection and test lines are shown in the same rather than in different colored light (Held \& Shattuck, 1971). Both classes of contingent aftereffect have been attributed to selective adaptation of detection mechanisms that are tuned to chromatic as well as spatial input. It has been proposed, for example, that orientation-specific color aftereffects (the McCollough effect) occur because a vertical grating in white light is normally signaled by the relative response rates of orange-vertical and blue-vertical detectors but one class of mechanism is in a suppressed state following the inspection period.

Interocular transfer of a perceptual aftereffect implies that detectors suppressed as the result of stimulation of one eye would normally have been engaged in processing the display subsequently presented to the other eye (see Movshon, Chambers, \& Blakemore, 1972). The McCollough effect is not obtained when the inspection stimuli are viewed by one eye and the test stimuli by the other eye (McCollough, 1965; Murch, 1972); such data suggest that color-tilt detectors have monocular specificity.

Regfests for reprints shorild be sent to Ray Over. Department al Prichology. Universily of Quecnsland, St. Lucia, Australia $40(1)$
However, the interocular transfer found with the tilt aftereffect (e.g., Movshon, Chambers, \& Blakemore, 1972) implies that spatial detectors can be driven binocularly. When the tilt aftereffect is induced with colored gratings, the wavelength selectivity in aftereffect obtained with the inspection and test lines seen by the same eye is no longer found when the two stimuli are viewed by separate eyes (Lovegrove \& Over, 1973). These data, together with results from other paradignis (see Coltheart, 1973; Over \& Wenderoth. 1974), suggest that binocularly driven spatial detectors in human vision are insensitive to wavelength and that mechanisms with chromatic and spatial tuning have monocular specificity.

\section{EXPERIMENT I}

If color-tilt detectors have monocular specificity, it should not be possible to induce contingent aftereffects when gratings are shown in white light to either eye after contour information has been presented to one eye and chromatic information to the other eye during inspection. Over, Long, and Lovegrove (1973) were unable to generate the McCollough effect under such conditions. However, MacKay and MacKay (1973) found that dichoptic inspection resulted in the normal McCollough effect in the eye that was adapted to color and in a reverse McCollough effect (the lines shown in white light having the same color appearance as during inspection) in the eye that was adapted to contours. They concluded that there might be binocularly responsive spatial detectors with complementary chromatic tuning for the two eyes.

Experiment I measures the tilt aftereffect when orientation of a colored grating is judged by each eye following monoptic (color and spatial information presented to a single eye) and dichoptic (color and 
Table 1

Means and Standard Errors (SE) of Aftereffects in Degrees

\begin{tabular}{|c|c|c|c|c|c|c|c|c|}
\hline \multirow{3}{*}{$\begin{array}{l}\text { Test } \\
\text { Color }\end{array}$} & \multicolumn{4}{|c|}{$\begin{array}{c}\text { Monoptic Inspection } \\
\text { Eye Test }\end{array}$} & \multicolumn{4}{|c|}{$\begin{array}{c}\text { Dichoptic Inspection } \\
\text { Eye Test }\end{array}$} \\
\hline & \multicolumn{2}{|c|}{ Contour } & \multicolumn{2}{|c|}{ Noncontour } & \multicolumn{2}{|c|}{ Contour } & \multicolumn{2}{|c|}{ Noncontour } \\
\hline & Same & Diff & Same & Diff & Same & Diff & Same & Diff \\
\hline Mean & 2.21 & 1.07 & 1.43 & 1.43 & 2.28 & 2.23 & 1.52 & 1.40 \\
\hline SE & .23 & .22 & .23 & .23 & .28 & .27 & .38 & .20 \\
\hline
\end{tabular}

Note: Monoptic inspection-color and contour to same eye, dichoptic inspection-color and contour to separate eyes, contour eye-eye shown contour during inspection, noncontour eye-eye shown either homogeneous white blank (monoptic) or homogeneous color (dichoptic) during inspection, test color (same)-inspection and test colors of same wavelength, test color (different)-inspection and test colors different in wavelength.

spatial information presented to different eyes) inspection. The tilt aftereffect resulting from munoptic inspection is selective to wavelength when the inspection and test figures are seen by the same eye, but not when they are viewed by separate eyes (Lovegrove \& Over, 1973). If color-tilt detectors have monocular specificity, the tilt aftereffect consequent upon dichoptic inspection should be insensitive to wavelength irrespective of whether the test stimulus is shown to the eye that was exposed to color or to contour. MacKay and MacKay's proposal suggests, however, that the tilt aftereffect in the eye that was exposed to color will be greater when the test grating is shown in the same colored light rather than in the complementary color. The reverse relationship should apply for the tilt aftereffect found in the eye that was exposed to contour.

\section{Method}

On each trial, the subject was exposed for $1 \mathrm{sec}$ to a grating of lines tilted $15^{\circ}$ from vertical prior to judging whether a test grating shown for $150 \mathrm{msec}$ appeared tilted clockwise or counterclockwise relative to verical. Both gratings were square wave with spatial frequency of $8 \mathrm{c} / \mathrm{deg}$, contrast of 0.6 , and space-average luminance of $17 \mathrm{~cd} / \mathrm{m}^{2}$. The diameter of inspection grating subtended $4^{\circ} 28^{\prime}$, and the test grating $3^{\circ} 12^{\prime}$. The test grating was always viewed by the right eye, and it was shown in either red light (Wratten filter 26) or green light (Wratten filter 55 ). The space-average luminance of the test grating was maintained at $15 \mathrm{~cd} / \mathrm{m}^{2}$. The inspection grating could be presented to the left or to the right eye, and in each case it could be shown in red or green light with the other eye stimulated by a blank tield shown in white light at a luminance of $14 \mathrm{~cd} / \mathrm{m}^{2}$ (monoptic inspection condition) or in white light with the other eye exposed at the same time to a red or green unpatterned field subtending $4^{\circ} 28^{\prime}$ and of luminance $17 \mathrm{~cd} / \mathrm{m}^{2}$ (dichoptic inspection condition). The stimuli were presented in a Scientific Prototype three-field tachistoscope, and polarizing filters enabled the inputs to the two eyes to be separated. External interval generators were used to control dark intervals between stimuli.

A cancellation method (Long \& Over. 1973) was used to measure the size of the tilt aftereffect. On the first trial under a specitic inspection condition, the test grating was shown at vertical, and its orientation was varied on subsequent trials by a double-random staircase procedure $\left(1^{\circ}\right.$ steps) until six reversals in tilt judgment occurred. The intertrial interval was $8 \mathrm{sec}$. Under a given inspection condition, the test grating was treated as having appeared vertical at the orientation midway between the values on which the subject gave opposite tilt judgments, and the aftereffect reflected the difference between this measure of apparent vertical and the baseline data obtained when the test grating was judged without prior exposure to the inspection grating.

The eight subjects had right-eye dominance (measured by the method described by Movshon et al., 1972), normal stereopsis (Julesz random-dot stereograms), and normal color vision (Ishihara test). Each subject was tested under both monoptic and dichoptic conditions, with the inspection grating shown to the left and to the right eye and paired with red and with green light. For four subjects, the test grating was always shown in red light, and for the other four, it was always presented in green light. The sequence of testing across inspection conditions was counterbalanced between subjects.

\section{Results}

Under each inspection condition, the apparent vertical was taken as the orientation midway between values on which the subject gave opposite tilt judgments, and the size of the aftereffect is given by the difference between these measures and baseline data. Mean aftereffects, together with standard errors, are shown in Table 1 for the different inspection conditions.

An analysis of variance and subsequent comparisons between means showed that the tilt aftereffect following monoptic inspection was selective to wavelength when the inspection and test gratings were viewed by the same eye, but not when they were presented to different eyes. This result replicates earlier data (Lovegrove \& Over, 1973). Dichoptic inspection, however, resulted in tilt aftereffects that did not differ significantly in size in terms of the color relationship between inspection and test; the sole basis for variation was in terms of whether the inspection and test gratings were shown to the same eye or to different eyes. The failure to induce wavelength-contingent tilt aftereffects following dichoptic inspection suggests that mechanisms tuned to chromatic and spatial input have monocular specificity.

\section{EXPERIMENT D}

The masking paradigm can be used as a further means of studying the response properties of visual detectors (see Blakemore \& Nachmias, 1971). Exposure to one grating impairs detection of another grating as a function of relative orientation, and masking is selective to wavelength when the two gratings are shown to the same eye (Lovegrove \& Over, 1973; May. 1972). Interocular transfer is found in orientation masking (Gilinsky \& Doherty, 1969), but the amount of masking is insensitive to wavelength when the inspection and test gratings are presented to different eyes (Maudarbocus \& Ruddock, 1973). As contingent masking and contingent aftereffects can be treated within a common framework (see Lovegrove \& Over, 1973), 
the question of interest in Experiment II was to compare wavelength selectivity in contour masking when the threshold for detection of a colored test grating was measured following exposure to color and spatial information under monoptic and dichoptic inspection conditions.

\section{Method}

A forward masking paradigm was used. On each trial, an inspection grating was shown for $500 \mathrm{msec}$, followed by a dark interval $(20 \mathrm{msec}$ ), and then the test stimulus (a grating on some trials and a random-element pattern on other trials). The subject's task was to identify which test stimulus had been shown, and the experiment neasured the period of test display needed for $75 \%$ accuracy in judgments under different inspection conditions. The stimuli were shown in separate channels of a Gerbrands three-field tachistoscope (Model T-3B-1), and polarizing filters were used when it was necessary to separate inputs to the two eyes. The inspection and test gratings were both vertical, and their other properties werc as described for Experiment I. The randomelcment field (space-average luminance $15 \mathrm{~cd} / \mathrm{m}^{2}$ ) was constituted of equally probable black and white squares (each $2^{\prime} \times 2$ ), and it subtended $3^{\circ} 12^{\prime}$ in diam.

Detection was measured by a blockwise-tracking method (see Lovegrove \& Over, 1973). Under each inspection condition, the period of display of the test stimulus was varied in ratio steps $(2,4$, $8,16 \ldots$ msec) over blocks of 12 trials (6 grating and 6 rand om-element presentations in random order) until the subject achieved $75 \%$ accuracy over a single block or bracketed this value between successive blocks. Detection was also measured when the test stimulus was shown without prior exposure to the inspection stimulus: the results under this condition served as a baseline against which the influence of the inspection stimulus could be established as the ratio of postinspection to preinspection detection durations.

Masking was measured under the monoptic and dichoptic inspection conditions described for Experiment I. Four subjects were tested; two viewed the test stimulus in red light and two in green light. The test stimulus was always viewed with the right eye. The inspection grating could be presented to the left or to the right eye, and in either case it could be shown in red or green light with the other eye stimulated by a blank field shown in white light at a luminance of $14 \mathrm{~cd} / \mathrm{m}^{2}$ (monoptic inspection condition) or in white light with the other eye exposed at the same time to a red or green unpatterned field subtending $4^{\circ} 28^{\prime}$ and of luminance $17 \mathrm{~cd} / \mathrm{m}^{2}$ (dichoptic inspection condition).

\section{Results}

Results for individual subjects were converted into masking ratios by dividing the detection threshold under each inspection condition by the baseline measure obtained when the test stimulus was shown without prior exposure to the inspection stimulus. Mean matios, together with standard errors, are shown in Table 2. An analysis of variance and subsequent comparisons between means showed that, with monoptic inspection, masking was selective to the color relationship between the inspection and test stimuli when both stimuli were presented to the same eye, but not when they were viewed by separate eyes. Mean masking under dichoptic conditions did not vary significantly in relation to whether the inspection and test colors were similar or different. This result
Table 2

Means and Standard Errors (SE) of Detection Ratios

\begin{tabular}{|c|c|c|c|c|c|c|c|c|}
\hline \multirow{3}{*}{$\begin{array}{c}\text { Test } \\
\text { Color } \\
\end{array}$} & \multicolumn{4}{|c|}{$\begin{array}{c}\text { Monoptic Inspection } \\
\text { Eye Test }\end{array}$} & \multicolumn{4}{|c|}{$\begin{array}{c}\text { Dichoptic Inspection } \\
\text { Eye Test }\end{array}$} \\
\hline & \multicolumn{2}{|c|}{ Contour } & \multicolumn{2}{|c|}{ Noncontour } & \multicolumn{2}{|c|}{ Contour } & \multicolumn{2}{|c|}{ Noncontour } \\
\hline & Same & Diff & Same & Diff & Same & Diff & Same & Diff \\
\hline $\begin{array}{l}\text { Mean } \\
\text { SE }\end{array}$ & $\begin{array}{r}2.48 \\
36\end{array}$ & $\begin{array}{r}1.34 \\
23\end{array}$ & $\begin{array}{r}1.64 \\
17\end{array}$ & $\begin{array}{r}1.55 \\
12\end{array}$ & $\begin{array}{r}2.32 \\
34\end{array}$ & $\begin{array}{r}2.66 \\
5 ?\end{array}$ & 1.71 & 1.66 \\
\hline
\end{tabular}

Note: Monoptic inspection-color and contour to same eye, dichoptic inspection-color and contour to separate eyes, contour eye-eye shown contour during inspection, noncontour eye-eye shown either homogeneous white blank (monoptic) or homogeneous color (dichoptic) during inspection, test color (same)-inspection and test colors of same wavelength, test color (different)-inspection and test colors different in wavelength.

applied for presentation of the test grating to the eye adapted by color and the eye adapted by the grating. These data support the conclusion from Experiment 1 that visual detectors tuned to chromatic and spatial input have monocular specificity.

\section{DISCUSSION}

Spatial masking and aftereffect have been attributed to adaptation of visual detectors sensitive to properties such as contour orientation and spatial frequency (see Blakemore \& Nachmias, 1971). The wavelength selectivity in perception found with these paradigms (Held \& Shattuck, 1971; Lovegrove \& Over, 1973; May, 1972) has suggested that at least some spatial detectors also have color tuning. The present experiments indicate that color-tilt detectors have monocular speciticity, whereas tilt detectors that are insensitive to wavelength have binocular response properties. Contour masking and aftereffect were found to vary with the color relationship between the inspection and test patterns when these stimuli were viewed by the same eye, but not when they were shown to separate eyes. However, masking and aftereffect were insensitive to the color relationship between the inspection and test stimuli when one eye was exposed to color and the other eye to contours during inspection. This applied irrespective of the eye to which the test stimulus was presented. These results are consistent with the demonstration (Over, Long, \& Lovegrove, 1973) that orientation-specific color aftereffects (the McCollough effect) are not induced by dichoptic adaptation to color and spatial information.

The proposal that color-tilt detectors in human vision have monocular specificity is open to a more direct test. May, Leftwich, and Aptaker (1974) adapted subjects to a colored grating before recording the evoked potential produced by another colored 
grating. Their data were selective to the orientation and wavelength relationship between the inspection and test stimuli in a manner consistent with psychophysical masking functions. However, the stimuli were displayed to the same eye at all stages of the experiment. It would be expected from the present data that wavelength selectivity in the evoked potential will be lost under conditions of interocular transfer and when the stimulation during inspection has entailed dichoptic presentation of chromatic and spatial information.

\section{REFERENCES}

Blakemore. C.. \& Nachmias. J. The orientation speciticity of two visual aftereffects, Journal of Physiology, 1971. 213. $15-1: 4$.

Coltheart, M. Colour-specificity and monocularity in the visual cortex. Vision Researh. 1973. 13. 2595-2598.

Gilinsky. A. S., \& Doherty, R. S. Interocular transter of orientation effects. Science, 1969, 164, 454-455.

Held, R., \& Shattuck, S. R. Color- and edge-sensitive channels in the human visual system: Tuning for orientation. Science, 1971, 174, 314-316.

LoNG. N., \& Over, R. Stereoscopic depth aftereffects with random-dot patterns. Vision $R$ esearch, 1973, 13. 1283-1287.

Lovegrove. W., \& Over, R. Colour selectivity in orientation masking and aftereffect. Vision Re'search, 1973, 13, 895-902.
MackaY, D. M., \& Mackay, V. Orientation-sensitive aftereffects of dichoptically presented colour and form. Nature. 1973, 242. 477.479.

Maudarbocus. A. H.. \& Ruddock, K. H. The influence of wavelength on visual adaptation to spatially periodic stimuli. Vision Research, 1973, 13, 993-998.

MaY, J. G. Chromatic adaptation of orientation and sizespecitic visual processes in man. Vision Reseurch, 1972, 12, $1509 \cdot 1517$.

May, J. G., Leftwich, D. A., \& Aptaker. P. Evoked poremtial correlates of adaptation to wavelength and orientation. Vision Reserarch. 1974. 14. 143-146.

McCorough, C. Color aldaptation of edge detectors in the human visual system. Science, 1965, 149, 1115-1116.

Movshon, J. A.. Chambers, C. E. I., \& Blakemore, C. Interocular transfer in normal humans, and those that lack sereopsis. Perception. 1972, 1. 483-490).

MuRCH, G. M. Binocular relationships in a size and color orientation-specitic aftereflect. Journal of Experimental Psycholog! . 1972, 93, 30-34.

Over, R., LoNG, N., \& Lovegrove, W. Absence of binocular interaction between spatial and color attributes of visual stimuli. Perception \& Psychophysics, 1973, 13, 534-540.

Over, R., \& Wenderoth, P. Is spatial masking selective to wavelength? Vision Research. 1974, 14, 157-158.

Sfoktler, R. Spatial vision. Ammal Review of Psychology, 1974. 25. $195-232$.

(Received for publication September 9, 1974; revisionl received November 18, 1974.) 